\title{
New food provision strategy for a colony of Barbary macaques (Macaca sylvanus): effects on social hierarchy?
}

\author{
Camillo Sandri ${ }^{1}$, Barbara Regaiolli ${ }^{2}$, Alex Vespiniani ${ }^{3}$ and Caterina Spiezio ${ }^{2 *}$ \\ ${ }^{1}$ Department of Animal Health Care and Management, Parco Natura Viva-Garda Zoological Park, Bussolengo, VR, Italy \\ ${ }^{2}$ Research and Conservation Department, Parco Natura Viva-Garda Zoological Park, Bussolengo, VR, Italy \\ ${ }^{3}$ Dipartimento di Neuroscienze, Università degli Studi di Parma, Italy
}

\begin{abstract}
In several zoological institutions, food is chopped into small pieces even though animals are skilled in processing much larger or even whole food items. Food chopping is usually aimed at enabling all individuals in a group to obtain enough food, preventing wastage, encouraging foraging behaviour, avoiding aggression during feeding. The aim of this study is to assess the impact of different food provision forms (chopped vs whole food) on the behaviour and social hierarchy of a colony of zoo Barbary macaques (Macaca sylvanus) hosted in Parco Natura Viva (Italy). The study was made of three conditions: the baseline-chopped food was provided; the Two Whole Food condition-two whole fruits and two whole vegetables per subject were provided; the One Whole Food condition-one whole fruit and one whole vegetable per subject were provided. For each condition, two daily 10-minute sessions per subject were run. Continuous focal animal sampling method was used to collect individual and social behaviours to assess the welfare of the Barbary macaques in the three different conditions. Moreover, for each condition, the dominance hierarchy was evaluated using the Clutton-Brock index (CBI) to assess the effects of different food provision forms on the social relationships between individuals. According to our results, macaques spent more time feeding in the baseline than in both the TWF and OWF condition. In addition, affiliative behaviours, particularly grooming, were performed more in the whole food condition than in the baseline. Within females, the hierarchy was not significantly affected by different food presentations and a decrease of aggressive behaviour in a whole food condition was found. Therefore, presenting whole food seemed to have a positive effect on the welfare of this colony, promoting natural behaviour and social cohesion. The presence of individual and social species-specific behaviours and the absence of stereotypic or abnormal behaviour underline an overall good welfare of the study Barbary macaques. In conclusion, to provide food to Barbary macaques in a more naturalist way-whole food-seems to be a good strategy to manage social relationships and improve the welfare of the animals.
\end{abstract}

\section{Introduction}

Several species of non-human primates face high risk of extinction as their population numbers are continuously and dramatically dropping in the wild [1]. Therefore, ex-situ conservation is necessary to ensure the survival of endangered species and the maintenance of viable populations. In modern zoological gardens, research on animal behaviour and physiology is necessary to improve the welfare, husbandry and breeding of non-human primates as well as other species under human care [2].

Proper nutrition and diet are fundamental for captive non-human primate health as well as physical and psychological well-being [3]. Thus, studies on feeding and nutrition in primates are needed to improve the diet composition and provisioning strategies in these species in captivity [3]. In many zoological institutions the food, particularly fruit and vegetables, is chopped into small pieces even though animals are skilled in processing much larger or even whole food items. Reasons for food chopping are to allow all individuals in a group to obtain enough food, to prevent wastage, to encourage foraging behaviour and to prevent intra-specific competition and aggression between group members during feeding [4]. However, scientific data are needed to improve the husbandry of animals in controlled environment $[2,4]$. Providing whole food, particularly fruit and vegetable, might have a positive effect on the welfare of captive primates, allowing for more opportunities to perform natural species-specific behaviours $[5,6]$. On the other hand, chopping food might lead to an increased risk of bacterial contamination and food wastage [4]. In addition, chopped food items dry out quickly, whereas whole food has less degradation time, occupying the animals more intensively [5].
A previous study on lion-tailed macaques (Macaca silenus) revealed that providing whole rather than chopped food increased the dietary diversity of all individuals and the time spent feeding [7]. Another study on Sulawesi crested black macaques (Macaca nigra) showed that whole food provision had no significant effect on feeding modalities and time and agonistic behaviours. However, whole food provision allowed subordinate macaques to obtain more food [4]. Similar positive effects on sociality have been found in siamangs (Symphalangus syndactylus) [5] and bonobos (Pan paniscus) [8]. Therefore, despite being widespread among zoos, chopping food seems not to be an optimal strategy $[2,5,7]$.

The aim of this study is to assess the effects of different food provision forms (chopped vs whole food) on individual and social behaviour of a colony of zoo Barbary macaques (Macaca sylvanus) hosted in Parco Natura Viva (Italy). In particular, the study aims at evaluating the impact of food provision form on the macaque welfare, comparing the behaviour of the animals in the presence of chopped rather than whole fruit and vegetable. Moreover, we aim at establishing

Correspondence to: Caterina Spiezio, Research and Conservation Department, Parco Natura Viva-Garda Zoological Park, Bussolengo, VR, Italy, E-mail: spiezio@parconaturaviva.it

Key words: Barbary macaques, food provision, whole food, animal welfare, hierarchy

Received: February 12, 2017; Accepted: March 07, 2017; Published: March 10, 2017 
whether different food provision forms would affect macaque social behaviour and hierarchy.

In the wild, Barbary macaques live in multi-male multi-female social groups. Males and females form their own hierarchies, protecting their social rank through aggression (especially among females) as well as formation of alliances with conspecifics, through grooming and other affiliative behaviours [9-16]. Wild Barbary macaques feed on fruits, leaves, seeds, grains and nuts, roots and tubers, wood, bark and stems and the diet varies according to the season $[13,17,18]$. Previous literature on the impact of different food preparation modalities on the welfare of captive macaques suggested a positive effect of whole food provision. Therefore, we expect that whole food preparation would be beneficial to the welfare of the study Barbary macaques [7].

\section{Materials and method}

\section{Study subjects and area}

This study involved a colony of 13 Barbary macaques, nine females and four males of different ages (Table 1). All subjects were housed at Parco Natura Viva, a zoological garden in Verona (Italy). The macaques were housed in a $1560 \mathrm{~m}^{2}$ naturalistic enclosure made of grassy areas, trees, rocks and stony cliffs, ropes, shelters and a water pool. Barbary macaques were fed once a day (in the morning) and water was available ad libitum. The diet consisted of fruits (apple, grape, banana, pineapple, papaya, kiwi, orange, strawberry, mixed-berries, avocado, peach, apricot, etc.) and vegetables (salad leaves and chicory, spinach, celery, cabbage, roots, fennel, tomato, zucchini, aubergine, potato, onion, etc.), legumes, seeds, cereals and mealworms. In particular, two types of fruit and two types of vegetable were provided daily. The fruit and vegetable types could vary daily, basing on the season and food availability. Fruits and vegetables were provided in six feeding points (wire-mesh baskets). A daily environmental enrichment program was provided to the macaques (manipulative devices to be opened to reach for food and small pieces of food scattered around in the enclosure or hidden in hay or straw mounds).

All subjects of the study were captive-born. The study was carried out through the live observation of spontaneous behaviours displayed by the macaques in their social context. No invasive or stressful techniques were used and the study procedure was in accordance with the EU Directive 2010/63/EU for animal research.

\section{Procedure and data collection}

The study was carried out from November 2015 to January 2016. It was made of three different conditions: the baseline (first period), the familiarization-Two Whole Food condition (TWF) (second period)and the One Whole Food condition (OWF) (third period). In all conditions, two types of fruits and two types of vegetables per day were provided. In the baseline, large fruits and large vegetables provided to the macaques were chopped in quarters or divided in smaller portions (e.g.: leaves or grapes). The food provision form of the baseline was the same provided to the group prior to the onset of the study. During the familiarization, the Two Whole Food condition, two large fruits and two large vegetables per type per subject were provided uncut, as a whole. This condition was planned to be an essential intermediate step to prepare the Barbary macaques to the new food provision form by providing them more food than necessary, to avoid competition over food. Finally, in the One Whole Food condition, one large fruit and one large vegetable per type per subject were provided uncut, as a whole. The mean $( \pm S D)$ weight of food provided daily to the macaques was $20.66 \pm 2.55 \mathrm{~kg}$ in the baseline, $23.30 \pm 4.37 \mathrm{~kg}$ in the TWF condition and $15.29 \pm 3.39 \mathrm{~kg}$ in the OWF condition.
For each condition, ten days of data collection were done. In particular, within each condition, twenty 10-min sessions per macaque were carried out (two sessions per day, one in the morning and one in the afternoon). A continuous focal animal sampling method was used to collect the duration of different individual and social behaviours (Table 2) [19]. Moreover, frequencies of agonistic interactions were also recorded and information on the dominant and subordinate individuals were collected [20,21]. For social agonistic behaviours, the analysis focused on both durations (for the entire group) and frequencies (only for females) of agonistic interactions [20,21].

In all conditions, the food was provided in the usual six feeding points, well spaced-out in the enclosure.

\section{Data analysis}

According to Kolmogorov-Smirnov tests, data were not normally distributed (Agonistic behaviour, OWF: $P<0.01$; locomotion, TWF: $P=0.017$; Resting, baseline: $P=0.031$, OWF: $P=0.033$; Cluster, baseline

Table 1. Study subjects. For each macaque, the table reports the subject name, the female name abbreviation (Abb.) used for the sociometric matrix construction, the sex ( $\mathrm{M}=$ male; $\mathrm{F}=$ female) and the age (years at the time of data collection).

\begin{tabular}{|c|c|c|c|}
\hline Subject & Abb. & Sex & Age \\
\hline Lucky & & M & 16 \\
\hline Black Betty & BB & F & 15 \\
\hline Gray & G & F & 7 \\
\hline Gaga & GA & F & 11 \\
\hline Maria & M & F & 12 \\
\hline Nicky & N & F & 14 \\
\hline Gray2 & G2 & F & 7 \\
\hline Honey & HO & F & 8 \\
\hline Butterfly & BU & F & 10 \\
\hline Puff & P & F & 6 \\
\hline Benny & & M & 6 \\
\hline Marco & & M & 6 \\
\hline Lime & & M & 4 \\
\hline
\end{tabular}

Table 2. Study ethogram. For both individual and social behaviours considered in the study, the table reports the behavioural categories and their definition

\begin{tabular}{|l|l|}
\hline Individual behaviours & \multicolumn{1}{|l|}{ Looking around, paying attention to the environment. } \\
\hline Attentive behaviour & Being asleep or relaxed. \\
\hline Resting & Looking for food away from the feeding points. \\
\hline Locomotion & Walking, running or climbing. \\
\hline Self-grooming & Self-cleaning of the fur or other part of the body. \\
\hline Feeding & Reaching for food in the feeding points. \\
\hline Social affiliative behaviour \\
\hline Sexual behaviour & $\begin{array}{l}\text { Mounting, placing feet on female calves and mating for several } \\
\text { seconds with pelvic thrust. Female genital inspection by males. } \\
\text { Female genital presentation to males. }\end{array}$ \\
\hline Grooming & $\begin{array}{l}\text { Cleaning the fur or other body parts of a macaque or being } \\
\text { cleaned. }\end{array}$ \\
\hline Affiliative behaviour & $\begin{array}{l}\text { Other affiliative social behaviours such as playing, sitting or } \\
\text { standing in contact. }\end{array}$ \\
\hline Cluster & Resting in close contact, huddling together with conspecifics. \\
\hline Social agonistic behaviour \\
\hline Dominance & $\begin{array}{l}\text { Dominance mount (no pelvic thrust) [19], chasing or } \\
\text { threatening; aggressive behaviours such as biting or hitting. } \\
\text { All dominance behaviours have specific facial expression (i.e. } \\
\text { round threat face, staring at the dominated conspecific [19]. }\end{array}$ \\
\hline Submission & $\begin{array}{l}\text { Being supplanted or threatened, fleeing, receiving an } \\
\text { aggression. All submissive behaviours have specific facial } \\
\text { expression (i.e. silent bared teeth) [19]. }\end{array}$ \\
\hline Out of sight & Being out of sight, the behaviour is not visible to the observer. \\
\hline Out of sight &
\end{tabular}


and TWF: $P=0.040$, OWF: $P<0.01$; Sexual behaviour, TWF and OWF: $P<0.01)$. Therefore, data were analysed using non-parametric tests. In particular, Friedman test was used to compare the durations of behavioural categories and frequencies of female agonistic behaviour in different conditions. Significance level was set at $P<0.05$. Moreover, we performed post-hoc pairwise comparisons between conditions using Wilcoxon test. Because of multiple comparisons, the significance-level was corrected using the Bonferroni adjustment [22]. The corrected significance level for three multiple comparisons was set at $P>0.017$. All tests were two-tailed.

In Barbary macaques the social hierarchy is more rigid in females than in males [9-16]. Therefore, effects of food provision forms on the macaque social rank were investigated only within females (the alpha male and the three juvenile subordinate males were excluded from this analysis). In particular, frequencies of female agonistic interactions were used to construct dominance double-entry matrices. For each female subject and for each condition, these matrices were used to calculate the CBI index by Clutton-Brock and colleagues [23] and determine the colony social hierarchy [24]. The CBI index for each macaque is given by the formula $\mathrm{CBI}=(\mathrm{B}+\mathrm{b}+1) /(\mathrm{L}+\mathrm{l}+1)$, in which " $\mathrm{B}=$ number of individuals whom the subject dominates, $\mathrm{b}=$ number of individuals whom those dominated by the subject in turn dominate, $\mathrm{L}=$ number of individuals who dominate the subject, $\mathrm{l}=$ number of individuals who dominate those dominating the subject" [24]. The CBI is used to calculate a linear dominance hierarchy: the higher is the CBI of each individual, the higher is the rank in the social group. In the current study, CBI indices were calculated for all conditions. Spearman correlations with Bonferroni adjustment for multiple comparisons $(P<0.017)$ were used to verify the relationship between the CBI indices in different conditions, to investigate the effect of different food provision forms on the social hierarchy of the Barbary macaque colony. The values in brackets in the result section are mean \pm SD in seconds.

\section{Results}

\section{Effect of food provision forms on individual behaviour}

Analysing the overall individual behaviour, Friedman test showed that differences between conditions were not significant $\left(\chi^{2}=-35.27\right.$, $P=1)$. As post-hoc analysis, Wilcoxon test using Bonferroni adjustment $(P<0.017)$ revealed no significant differences between baseline (8882.46 \pm 1129.52$)$ and both TWF (8794.08 \pm 727.12$) \quad(Z=-0.384$, $P=0.704)$ and OWF (8895.85 \pm 588.13$)(Z=-0.105, P=0.920)$. Similarly, no significant differences emerged between the TWF and OWF $(Z=-$ $0.035, P=0.977)$.

When each individual behaviour was considered separately, Friedman test showed that differences between conditions were significant for attentive behaviour $\left(\chi^{2}=7.38, P=0.025\right)$ and feeding $\left(\chi^{2}=14, P=0.001\right)$. No significant differences were found for other behavioural categories (foraging: $\chi^{2}=1.080, P=0.583$; locomotion: $\chi^{2}=4.15, P=0.126$; resting: $\chi^{2}=0.81, P=0.667$; self-grooming: $\chi^{2}=3.23$, $P=0.199)$. Wilcoxon test using Bonferroni adjustment $(P<0.017)$ revealed that the time spent feeding was higher in the baseline than in the TWF $(Z=-2.900, P=0.004)$ and the OWF $(Z=-3.110, P=0.002)$. No significant differences were found between the baseline and both the TWF and OWF for other individual behaviours $(P>0.017)$ (Figure 1, Table 3). In addition, no significant differences in any individual behaviour were found between the TWF and OWF $(P>0.017)$ (Figure 1, Table 3).

\section{Effect of food provision forms on social behaviour and hierarchy}

Regarding overall social behaviours, Friedman test showed that differences between conditions were not significant $\left(\chi^{2}=1.38, P=0.502\right)$. Wilcoxon test using Bonferroni adjustment $(P<0.017)$ revealed no significant differences between baseline $(2872.15 \pm 1016.12)$ and both TWF (3164.38 \pm 731.45$)(Z=-0.664, P=0.509)$ and OWF $(3015 \pm 562.93)$ $(Z=-0.594, P=0.555)$. Moreover, no significant differences between the TWF and OWF were found $(Z=-0.035, P=0.977)$.

Within social behaviours, Friedman test showed that differences between conditions were not significant for overall affiliative behaviour $\left(\chi^{2}=1.85, P=0.397\right)$, whereas for overall agonistic behaviour the $P$-value approached but failed to reach significance level $\left(\chi^{2}=5.54, P=0.063\right)$. Wilcoxon test using Bonferroni adjustment $(P<0.017)$ revealed no

Table 3. Individual and social behaviours in the three conditions. Individual behaviours are reported in rows 1 to 6 , social affiliative behaviours in rows 7 to 10 . For each condition, the table reports the mean duration $( \pm \mathrm{SD})$ in seconds of different behavioural categories. The Wilcoxon test $Z$ and $P$ value for the comparison between the baseline and the TWF condition (B vs TWF), between the baseline and the OWF condition (B vs OWF) and between the TWF and OWF conditions are also reported. Asterisks indicate a significant difference between conditions (Bonferroni adjust: $P<0.017$ )

\begin{tabular}{|c|c|c|c|c|c|c|}
\hline & Baseline (B) & TWF condition & OWF condition & B vs TWF & B vs OWF & TWF vs OWF \\
\hline \multirow{2}{*}{ Attentive behaviour } & \multirow{2}{*}{$2945.08 \pm 988.43$} & \multirow{2}{*}{$3078.08 \pm 759.91$} & \multirow{2}{*}{$3553.31 \pm 921.31$} & $Z=-0.384$ & $Z=-2.132$ & $Z=-1.433$ \\
\hline & & & & $P=0.704$ & $P=0.033$ & $\mathrm{P}=0.153$ \\
\hline \multirow{2}{*}{ Feeding } & \multirow{2}{*}{$1444.23 \pm 353.81$} & \multirow{2}{*}{$859.62 \pm 521.36$} & \multirow{2}{*}{$437.62 \pm 333.58$} & $Z=-2.900$ & $Z=-3.110$ & $Z=-1.992$ \\
\hline & & & & $P=0.004^{*}$ & $P=0.002^{*}$ & $P=0.047$ \\
\hline \multirow{2}{*}{ Foraging } & \multirow{2}{*}{$2886.62 \pm 1008.60$} & \multirow{2}{*}{$3290.15 \pm 611.57$} & \multirow{2}{*}{$3393.54 \pm 1049.67$} & $Z=-1.782$ & $Z=-1.013$ & $Z=-0.175$ \\
\hline & & & & $P=0.075$ & $P=0.313$ & $P=0.865$ \\
\hline \multirow{2}{*}{ Locomotion } & \multirow{2}{*}{$419.23 \pm 75.77$} & \multirow{2}{*}{$345.38 \pm 134.23$} & \multirow{2}{*}{$327.69 \pm 94.80$} & $Z=-1.293$ & $Z=-2.201$ & $Z=-0.454$ \\
\hline & & & & $P=0.197$ & $P=0.028$ & $P=0.653$ \\
\hline \multirow{2}{*}{ Resting } & \multirow{2}{*}{$683.69 \pm 634.94$} & \multirow{2}{*}{$834.85 \pm 726.36$} & \multirow{2}{*}{$548 \pm 593.91$} & $Z=-0.357$ & $Z=-0.454$ & $Z=-1.572$ \\
\hline & & & & $P=0.718$ & $P=0.653$ & $P=0.116$ \\
\hline \multirow{2}{*}{ Self-grooming } & \multirow{2}{*}{$503.62 \pm 308.34$} & \multirow{2}{*}{$386 \pm 425.38$} & \multirow{2}{*}{$635.69 \pm 391.29$} & $Z=-1.153$ & $Z=-0.664$ & $Z=-1.712$ \\
\hline & & & & $P=0.250$ & $P=0.509$ & $P=0.087$ \\
\hline \multirow{2}{*}{ Affiliative behaviour } & \multirow{2}{*}{$638 \pm 648.18$} & \multirow{2}{*}{$752.85 \pm 619.02$} & \multirow{2}{*}{$279.54 \pm 213.67$} & $Z=-0.785$ & $Z=-1.223$ & $Z=-2.589$ \\
\hline & & & & $P=0.435$ & $P=0.222$ & $P=0.010^{*}$ \\
\hline \multirow{2}{*}{ Cluster } & \multirow{2}{*}{$799.54 \pm 448.95$} & \multirow{2}{*}{$337.08 \pm 322.43$} & \multirow{2}{*}{$143.38 \pm 257.03$} & $Z=-2.981$ & $Z=-3.059$ & $Z=-1.718$ \\
\hline & & & & $P=0.003^{*}$ & $P=0.002^{*}$ & $P>0.05$ \\
\hline \multirow{2}{*}{ Grooming } & \multirow{2}{*}{$1037.92 \pm 455.07$} & \multirow{2}{*}{$1655.69 \pm 987.74$} & $2226.08 \pm 662.73$ & $Z=-1.852$ & $Z=-3.180$ & $Z=-2.062$ \\
\hline & & & $2226.08 \pm 662.13$ & $P=0.064$ & $P=0.001^{*}$ & $P=0.039$ \\
\hline Sexual behaviour & & & & $Z=-0.489$ & $Z=-2.310$ & $Z=-1.223$ \\
\hline sexual benaviour & $48.38 \pm 65.04$ & $38.31 \pm 59.48$ & $19.1 / \pm 2 / .3 /$ & $P=0.624$ & $P=0.021$ & $P=0.222$ \\
\hline
\end{tabular}




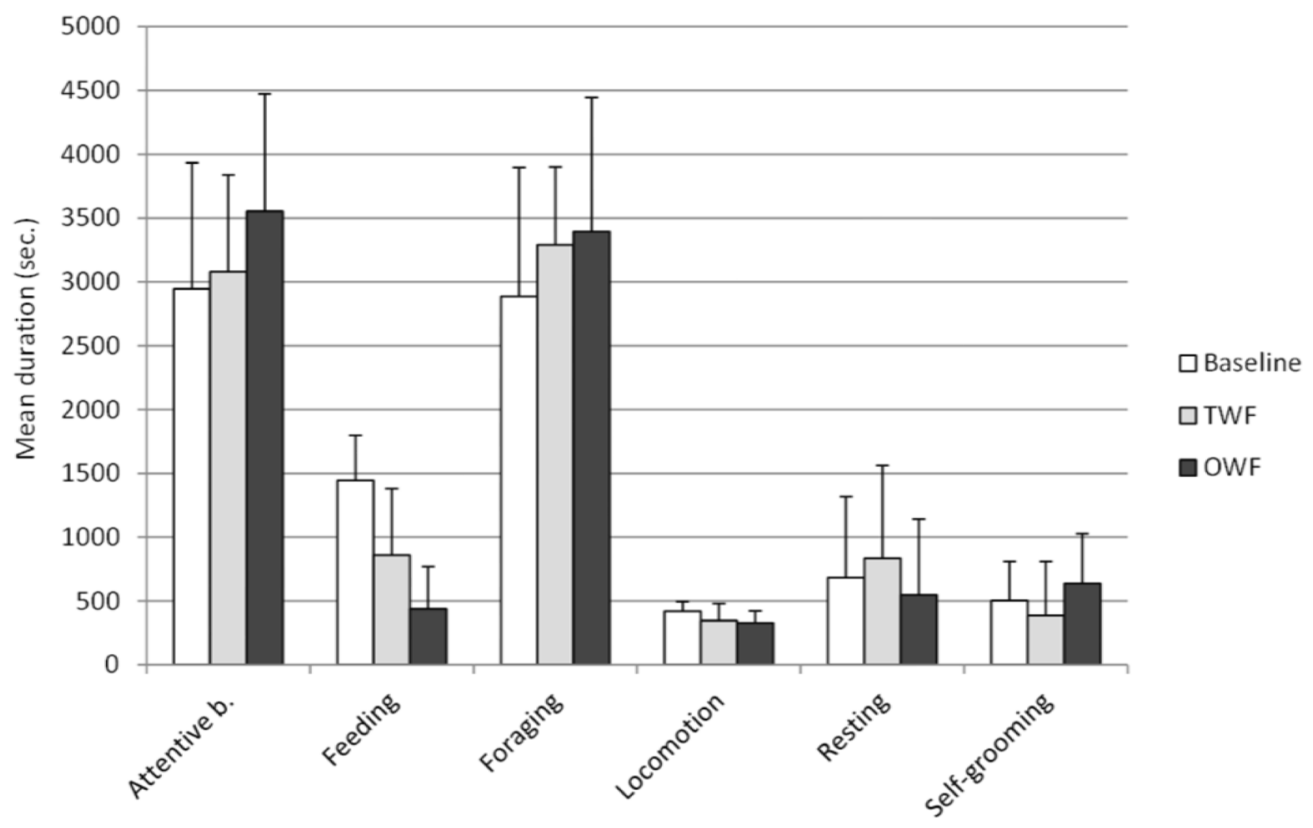

Figure 1. Clustered bar graph reporting individual behaviours of the study macaques in the three different conditions (TWF=Two whole food condition; OWF=One whole food condition Error bars stand for standard deviation. For statistical analysis of differences between conditions (Table 3)

significant differences for overall affiliative behaviours between baseline (2523.85 \pm 996.18$)$ and both TWF $(2783.92 \pm 879.87)(Z=-0.524$; $P=0.603)$ and $\mathrm{OWF}(2668.77 \pm 529.40)(Z=-0.594 ; P=0.555)$. Moreover, no significant differences between the TWF and OWF were found $(Z=-$ $0.105, P=0.920)$.

Regarding overall agonistic behaviours, Wilcoxon test using Bonferroni adjustment $(P<0.017)$ revealed no significant differences between the baseline $(120.77 \pm 59.09)$ and both the TWF $(93.08 \pm 41.25)$ $(Z=-1.433 ; P=0.153)$ and $\operatorname{OWF}(110.77 \pm 150.39)(Z=-1.153 ; P=0.250)$. Moreover, no significant differences between the TWF and OWF were reported $(Z=-1.048, P=0.294)$.

When each social affiliative behaviour was considered separately, Friedman test showed that differences between conditions were significant for cluster $\left(\chi^{2}=15.35, P=0.001\right)$ and grooming $\left(\chi^{2}=15.38\right.$, $P=0.001$ ), whereas no significant differences were found for other behavioural categories (affiliative behaviour: $\chi^{2}=4.19, \quad P=0.123$; sexual behaviour: $\left.\chi^{2}=2.35, P=0.301\right)$. Wilcoxon test using Bonferroni adjustment $(P<0.017)$ revealed that macaques spent more time in cluster in the baseline than in the TWF $(Z=-2.981, P=0.003)$ and in the $\operatorname{OWF}(Z=-3.059, P=0.002)$, whereas no significant differences emerged between the TWF and the OWF (Figure 2, Table 3). On the other hand, grooming was performed significantly less in the baseline than in the TWF $(Z=-3.180, P=0.001)$. However, no significant differences emerged between the baseline and the OWF and between the TWF and OWF (Figure 2, Table 3).

\section{Female agonistic behaviour and social hierarchy}

First, the mean frequency \pm SD of agonistic behaviour in female Barbary macaques of the study was $5.44 \pm 5.15$ in the baseline, $5 \pm 5.05$ in the TWF and $2.22 \pm 2.86$ in the OWF. Friedman test revealed that differences between conditions were significant $\left(\chi^{2}=7.72, P=0.021\right)$. Wilcoxon test using Bonferroni adjustment $(P<0.017)$ revealed that female agonistic behaviours were significantly more frequent in the baseline than in the OWF $(W=36, P=0.010)$. However, no differences emerged between the baseline and the TWF $(W=1, P>0.05)$ and between the TWF and OWF ( $W=15, P=0.05)$.

Figures 3-5, report the sociometric matrices of agonistic interactions of female Barbary macaques of the study group. The social hierarchies were constructed basing on the CBI indices calculated from the matrices and are reported in Figure 6. Descriptive analysis revealed that the CBI indices and therefore the dominance hierarchy varied over different conditions and variation was greater for low-ranking females. However, significant positive correlations were found between the baseline and both the TWF (Spearman $r h o=0.921, P<0.001$ ) and OWF (Spearman $r h o=0.924, P<0.001$ ) and between the TWF and OWF (Spearman $r h o=0.958, P<0.001$ ), suggesting no statistical differences in the hierarchy between conditions.

\section{Discussion and conclusion}

First, over the three different conditions, all the study Barbary macaques displayed a species-specific behavioural repertoire and no abnormal behaviours were found. Therefore, the colony seems to be in an overall good welfare [6].

Regarding the effect of different food provision forms on the macaque behaviour, we found that among individual behaviours, the time spent feeding was significantly lower in both whole food conditions than in the baseline $[11,12]$. This finding is not in agreement with previous research on lion-tailed macaques, reporting an increase in the time spent feeding in the presence of whole rather than chopped food [7]. However, this discrepancy might be due to different procedures between the previous and the current study. Indeed, we collected data not only during food provision but also throughout the day, covering a wider time span. Alternatively, it is possible that providing food in pieces may require more time to the macaques to consume it. Also, macaques may invest more time collecting several pieces and looking for their favourite food items inside the basket. In addition, no differences were reported in any individual behaviour between the TWF and OWF conditions, in which different amounts 


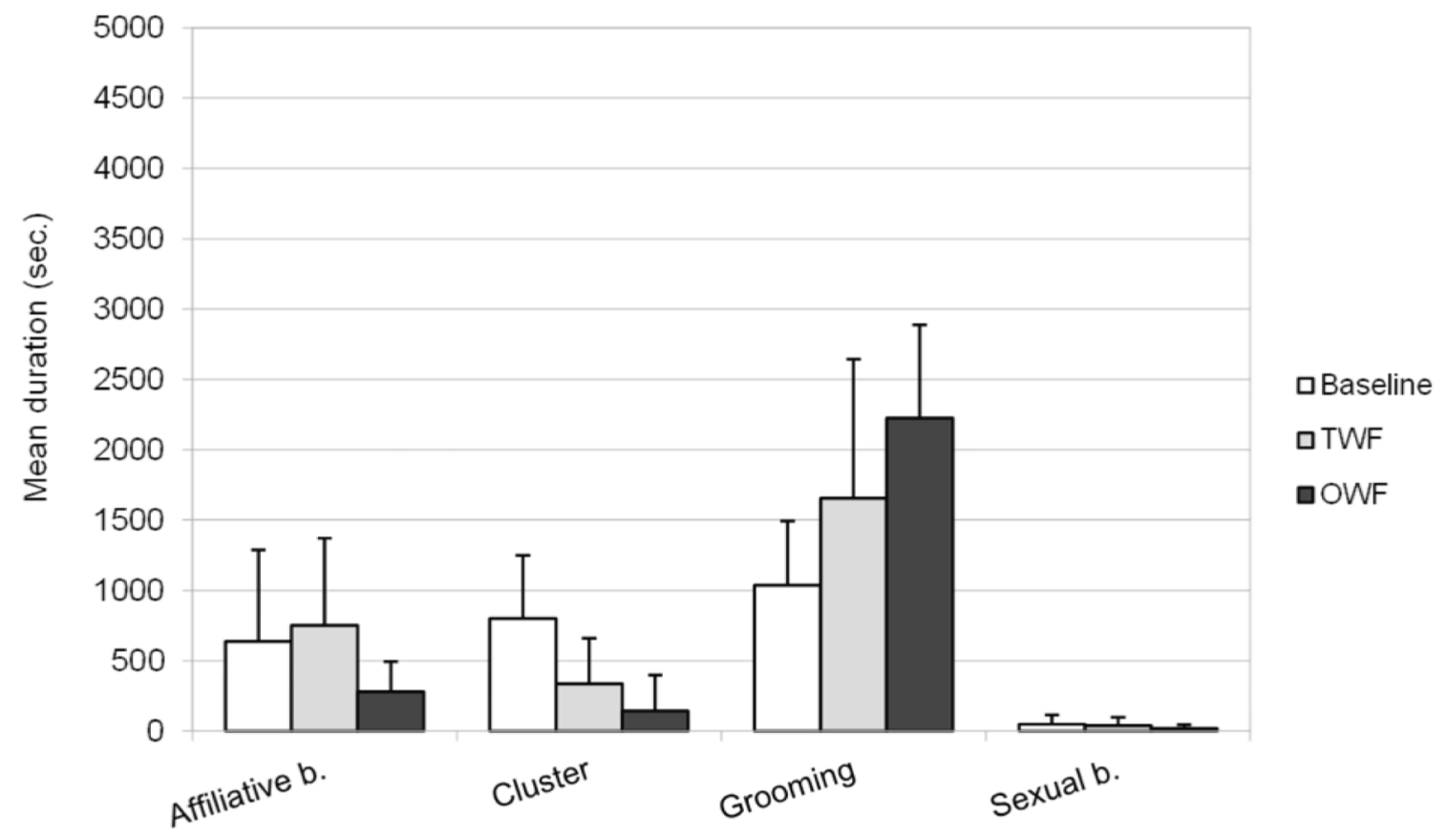

Figure 2. Clustered bar graph reporting social affiliative behaviours of the study macaques in the three different conditions (TWF=Two whole food condition; OWF=One whole food condition. Error bars stand for standard deviation. For statistical analysis of differences between conditions (Table 3)

\begin{tabular}{|c|c|c|c|c|c|c|c|c|c|c|c|c|}
\hline & BB & BU & $\mathbf{G}$ & G2 & GA & HO & M & $\mathbf{N}$ & $P$ & B & b & CBI \\
\hline BB & - & 1 & & & 1 & 1 & & 4 & & 4 & 9 & 14 \\
\hline BU & & - & & & & & 1 & & 1 & 2 & 2 & 0.21 \\
\hline G & & 1 & - & & 2 & 5 & 2 & 1 & 3 & 6 & 11 & 18 \\
\hline G2 & & 3 & & - & & 2 & 1 & 6 & 1 & 5 & 7 & 3.25 \\
\hline GA & & 1 & & 1 & - & 2 & & 3 & & 4 & 10 & 5 \\
\hline HO & & 1 & & & & - & & & 2 & 2 & 3 & 0.75 \\
\hline$M$ & & & & & & & - & & 1 & 1 & 1 & 0.25 \\
\hline $\mathbf{N}$ & & 1 & & & & & & - & & 1 & 2 & 0.5 \\
\hline $\mathbf{P}$ & & 1 & & & & & & & - & 1 & 2 & 0.19 \\
\hline L & 0 & 7 & 0 & 1 & 2 & 4 & 3 & 4 & 5 & & & \\
\hline$I$ & 0 & 16 & 0 & 2 & 0 & 3 & 8 & 3 & 15 & & & \\
\hline
\end{tabular}

Figure 3. Sociometric matrix for female Barbary macaques constructed basing on agonistic interactions in the baseline. For each dyad, dominant individuals are reported in rows whereas subordinate individuals are in columns. The last two columns report the parameters B and b whereas the last two rows report the parameters $\mathrm{L}$ and 1 used to calculate the CBI index: $\mathrm{CBI}=(\mathrm{B}+\mathrm{b}+1) /(\mathrm{L}+\mathrm{l}+1)$, visible in the last column 


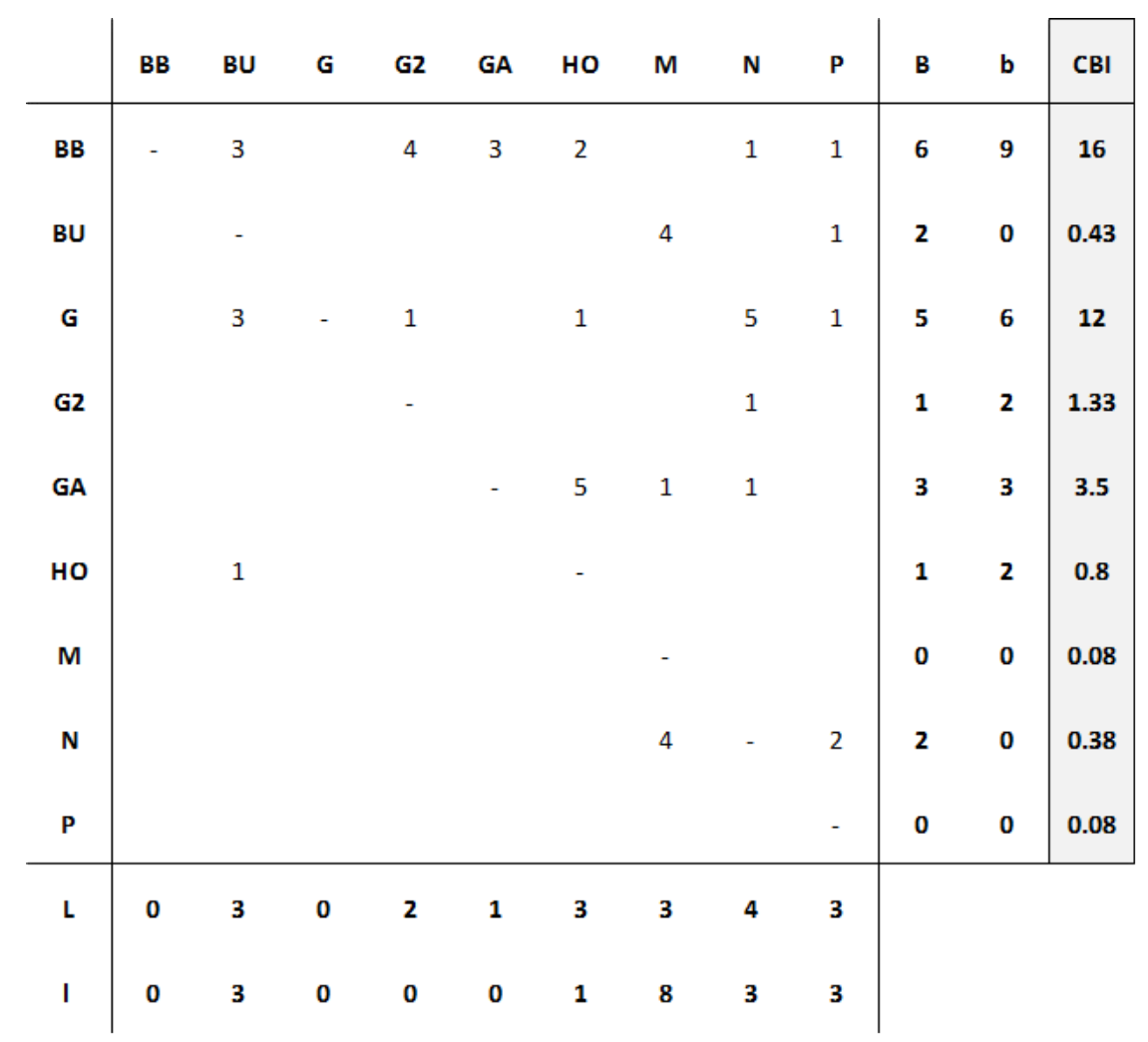

Figure 4. Sociometric matrix for female Barbary macaques constructed basing on agonistic interactions in the Two Whole Food condition. For each dyad, dominant individuals are reported in rows whereas submissive individuals are in columns. The last two columns report the parameters $\mathrm{B}$ and $\mathrm{b}$ whereas the last two rows report the parameters $\mathrm{L}$ and 1 used to calculate the $\mathrm{CBI}$ index: $\mathrm{CBI}=(\mathrm{B}+\mathrm{b}+1) /(\mathrm{L}+1+1)$, visible in the last column

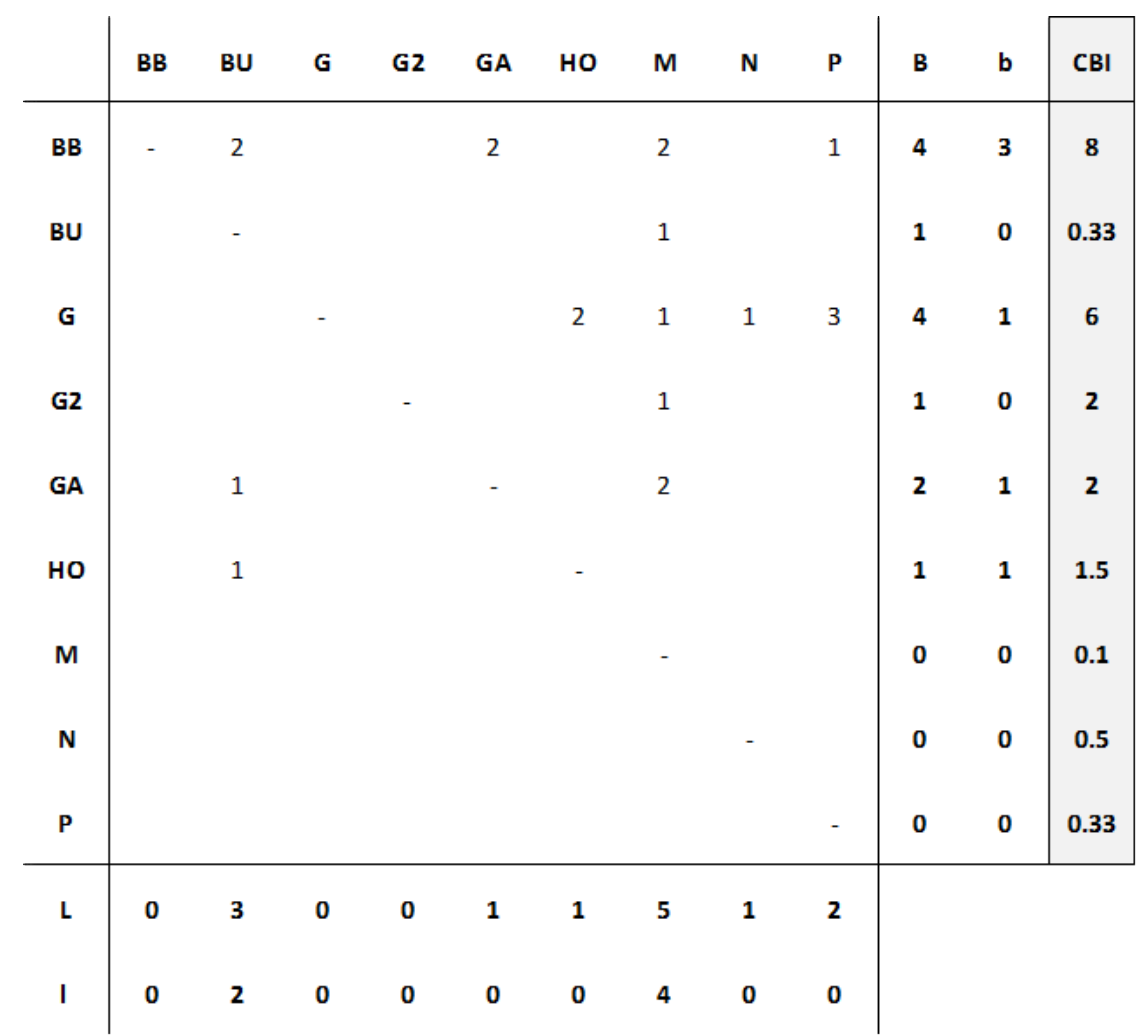

Figure 5. Sociometric matrix for female Barbary macaques constructed basing on agonistic interactions in the One Whole Food condition. For each dyad, dominant individuals are reported in rows whereas submissive individuals are in columns. The last two columns report the parameters $\mathrm{B}$ and $\mathrm{b}$ whereas the last two rows report the parameters $\mathrm{L}$ and $1 \mathrm{used}$ to calculate the $\mathrm{CB}$ index: $\mathrm{CBI}=(\mathrm{B}+\mathrm{b}+1) /(\mathrm{L}+\mathrm{l}+1)$, visible in the last column 


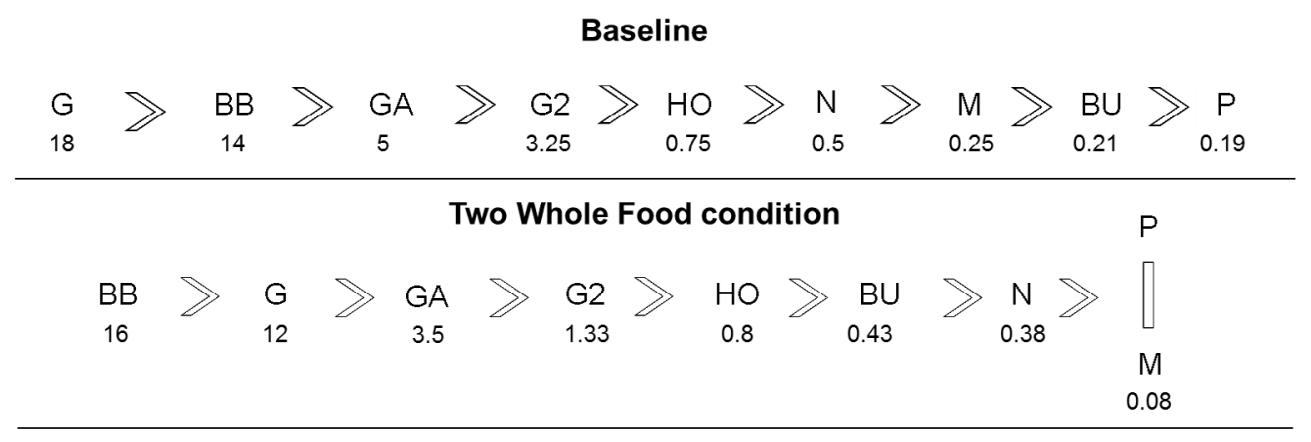

One Whole Food condition

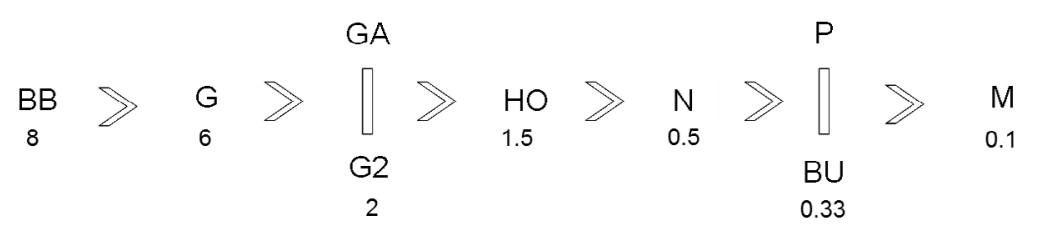

Figure 6. Social hierarchies of female Barbary macaques in different conditions. For each condition, the hierarchy was constructed basing on the CBI indices, which is reported in the figure under each subject name

of whole fruit and vegetables (23.30 kg vs $15.29 \mathrm{~kg}$ respectively) were provided. Therefore, food provision form rather than food quantity seems to affect Barbary macaque behaviour.

Importantly, this study aimed at assessing the impact of different food provision forms on the social behaviour and hierarchy of the colony, to verify whether more naturalistic food provision might affect competition between captive macaques. Within affiliative behaviours, cluster and behaviours such as playing and being in contact decreased in the presence of whole food. On the other hand, grooming increased over conditions and was performed significantly more in the OWF than in the baseline. The increase of grooming is relevant, as this behaviour is fundamental for Barbary macaques to develop and strengthen social bonds, necessary for group stability [9-16,25]. Barbary macaques use grooming also to reconcile and alleviate social tension resulting from competition [26]. However, the trend toward a reduction in agonistic behaviour of the entire group and the decreased frequency of female agonistic interactions over the three conditions seem not to support this view. The increase of grooming in the study group seems mostly to be associated with the need to create and strengthen social bonds. Furthermore, previous studies on captive rhesus macaque revealed that an exaggerated increase in grooming can lead to maladaptive behaviours such as over-grooming [25]. However, literature on semi-free ranging Barbary macaques and other non-human primates reported grooming time-budgets similar to that found in the current study $[27,28]$. Moreover, in some circumstances, Barbary macaques might perform this behaviour even for longer time [28]. In addition, self-directed behaviours that can be maladaptive if performed in excess [6] did not differ over the study conditions, suggesting an overall welfare of the animals. Therefore, providing whole food seems to have a positive impact on the welfare of the study macaques, allowing them to perform their natural behavioural repertoire $[4,6]$ as well as promoting group cohesion and stability [29-31].

Regarding agonistic behaviour performed by the entire group, macaques showed a trend toward less aggressive interactions $(\mathrm{P}=0.063)$ in the TWF and OWF than in the baseline. Similar findings were found within females. Indeed, as in Barbary macaques the social hierarchy is more rigid in females than in males [9-16], we investigated the effect of different food provision forms on agonistic behaviours and hierarchy in the study females. Our results underlined a decrease in the frequency of agonistic interactions in the whole food conditions than in the baseline, especially in the One Whole Food condition. In addition, the sociometric matrices and the CBI indices suggested qualitative changes in the female macaque hierarchies, particularly among low-ranking individuals. However, as the CBI indices of different conditions were strongly correlated $(P<0.001)$, statistical analysis did not confirm differences in social hierarchy. Therefore, whole food provision seems not to alter the social stability of the study Barbary macaques.

Finally, providing Barbary macaques with whole food seems to promote the performance of affiliative behaviours rather than incentivising competition between individuals $[4,5]$. It is possible that through grooming, low-ranking female macaques create and strengthen their social bonds with higher-ranking individuals to increase access to food resources. Therefore, whole food provision, especially in the One Whole Food condition, seems to have more positive effects on the social dynamics and stability of Barbary macaque groups, promoting the performance of natural social behaviours [9-16]. This finding is in agreement with previous literature on food preparation in non-human primates, suggesting that providing macaques with sufficient and not excessive amount of whole rather than chopped food might have a positive effect on their welfare and social life $[4,5,8]$.

In conclusion, contrary to previous belief, this study highlights that naturalistic food provision forms might improve the husbandry and social dynamics of non-human primates under human care, reducing intra-specific competition and strengthening social bonds.

\section{Acknowledgment}

We would like to thank Dr. Cesare Avesani Zaborra for allowing this study to take place in Parco Natura Viva. Very special thanks should go to Professor Paola Maria Valsecchi of the University of Parma for her steady support and advice during the study. Finally, we would like to thank Daniela Galietta, Alberto Luisi and Simone Parodi, Parco Natura Viva non-human primate zoo-keepers, for their support and collaboration in the study. 


\section{References}

1. Schwitzer C, Mittermeier RA, Rylands AB, Chiozza F, Williamson EA, et al. (2015) Primates in Peril: The World's 25 Most Endangered Primates 2014-2016. IUCN SSC Primate Specialist Group (PSG), International Primatological Society (IPS), Conservation International (CI) and Bristol Zoological Society, Arlington, VA pp: 93.

2. Melfi VA (2009) There are big gaps in our knowledge, and thus approach, to zoo animal welfare: a case for evidence-based zoo animal management. Zoo Biol 28: 574-588. [Crossref]

3. Gray H (2008) Feeding strategies to promote welfare and conservation of captive endangered primates. Master of Science dissertation, Imperial College London.

4. Green K, Taylor L, Plowman A (2007) Should zoo food be chopped? BIAZA Research Newsletter 8(3).

5. Orgeldinger M (1995) Feeding captive siamangs: a nutrition analysis and some proposals to enhance feeding in a more natural manner. IZN (International Zoo News) 424: 223-235.

6. Hosey G, Melfi V, Pankhurst S (2013) Zoo Animals: Behaviour, Management, and Welfare. Oxford: Oxford University Press.

7. Smith A, Lindburg DG, Vehrencamp S (1989) Effect of food preparation on feeding behaviour of lion-tailed macaques. Zoo Biology 8: 57-65.

8. White FJ (1992) Meat and fruit sharing in Pan paniscus. 14th Congress of the International Primatological Society, Strasbourg, France.

9. Deag J (1973) Intergroup encounters in the wild Barbary macaque (Macaca sylvanus 1). In: Michael R, Crook J (Eds.), Comparative ecology and behaviour of primates. New York: Academic Press pp: 316-370.

10. Kuester J, Paul A (1999) Male migration in Barbary macaques (Macaca sylvanus) at Affenberg Salem. Int J Primatol 20: 85-106.

11. Mehlman PT (1989) Comparative Density, Demography, and Ranging Behavior of Barbary Macaques (Macaca sylvanus) in Marginal and Prime Conifer Habitats. Int J Primatol 10: 269-292.

12. Ménard N, Vallet D (1993) Population dynamics of Macaca sylvanus in Algeria: An 8-year study. Am J Primatol 30: 101-118.

13. Rowe N (1996) The pictorial guide to the living primates. East Hampton, NY: Pogonias Press.

14. Preuschoft S, Paul A, Keuster J (1998) Dominance styles of female and male Barbary macaques (Macaca sylvanus). Behaviour 135: 731-735.

15. Shutt K, MacLarnon A, Heistermann M, Semple S (2007) Grooming in Barbary macaques: better to give than to receive? Biol Lett 3: 231-233. [Crossref]
16. Thierry B (2004) Social epigenesis. In: Thierry B, Singh M, Kaumanns W (Eds.), Macaque societies: A model for the study of social organization. United Kingdom: Cambridge University Press, pp: 267-288

17. Mehlman PT (1988) Food resources of the wild Barbary macaque (Macaca sylvanus) in high-altitude fir forest, Ghomaran Rif, Morocco. Journal of Zoology 214: 469-490.

18. Ménard N, Vallet D (1997) Behavioral responses of Barbary macaques (Macaca sylvanus) to variations in environmental conditions in Algeri. Am J Primatol 43: 285-304.

19. Maestripieri D (1997) Gestural Communication in Macaques: Usage and Meaning of Nonvocal Signals. Evolution of Communication 1: 193-222.

20. Altmann J (1974) Observational study of behavior: sampling methods. Behaviour 49 227-267. [Crossref]

21. Koenig A, Larney E, Lu A, Borries C (2004) Agonistic behavior and dominance relationships in female phayre's leaf monkeys - preliminary results. Am J Primatol 64: 351-357.

22. Snedecor GW, Cochran WG (1989) Statistical Methods. Ames, IA: Iowa State University Press.

23. Clutton-Brock TH, Albon SD, Gibson RM, Guinness FE (1979) The logical stag: adaptive aspects of fighting in red deer (Cervus elaphus L.). Animal Behaviour 27: 211-225.

24. Bang A, Deshpande S, Sumana A, Gadagkar R (2010) Choosing an appropriate index to construct dominance hierarchies in animal societies: a comparison of three indices. Animal Behavior 79: 631-636.

25. Beisner BA, Jackson ME, Cameron AN, McCowan B (2011) Detecting instability in animal social networks: genetic fragmentation is associated with social instability in rhesus macaques. PLoS One 6: e16365. [Crossref]

26. McFarland R, Majolo B (2011) Grooming coercion and the post-conflict trading of social services in wild Barbary macaques. PLoS One 6: e26893. [Crossref]

27. Henazi SP, Barrett L (1999) The value of grooming to female primates. Primates 40 47-59. [Crossref]

28. Roubová V, Konečná M, Šmilauer P, Wallner B (2015) Whom to groom and for what? Patterns of grooming in female Barbary macaques (Macaca sylvanus). PLoS One 10: e0117298. [Crossref]

29. Dunbar RIM (1988) Primate Social Systems. London: Chapman and Hall.

30. Dunbar RIM (1992) Time: a hidden constraint on the behavioural ecology of baboons. Behav Ecol Sociobiol 31: 35-49.

31. Fruteau C, Voelkl B, van Damme E, Noe R (2009) Supply and demand determine the market value of food providers in wild vervet monkeys. Proceedings of the National Academy of Sciences 106: 12007-12012.

Copyright: (C2017 Spiezio C. This is an open-access article distributed under the terms of the Creative Commons Attribution License, which permits unrestricted use, distribution, and reproduction in any medium, provided the original author and source are credited. 